\title{
Metabolic diseases and pro- and prebiotics: Mechanistic insights
}

\author{
Yukiko K Nakamura and Stanley T Omaye*
}

\begin{abstract}
Metabolic diseases, such as obesity and type 2 diabetes, are world-wide health problems. The prevalence of metabolic diseases is associated with dynamic changes in dietary macronutrient intake during the past decades. Based on national statistics and from a public health viewpoint, traditional approaches, such as diet and physical activity, have been unsuccessful in decreasing the prevalence of metabolic diseases. Since the approaches strongly rely on individual's behavior and motivation, novel science-based strategies should be considered for prevention and therapy for the diseases. Metabolism and immune system are linked. Both overnutrition and infection result in inflammation through nutrient and pathogen sensing systems which recognize compounds with structural similarities. Dietary macronutrients (fats and sugars) can induce inflammation through activation of an innate immune receptor, Toll-like receptor 4 (TLR4). Long-term intake of diets high in fats and meats appear to induce chronic systemic low-grade inflammation, endotoxicity, and metabolic diseases. Recent investigations support the idea of the involvement of intestinal bacteria in host metabolism and preventative and therapeutic potentials of probiotic and prebiotic interventions for metabolic diseases. Specific intestinal bacteria seem to serve as lipopolysaccharide (LPS) sources through LPS and/or bacterial translocation into the circulation due to a vulnerable microbial barrier and increased intestinal permeability and to play a role in systemic inflammation and progression of metabolic diseases. This review focuses on mechanistic links between metabolic diseases (mainly obesity and type 2 diabetes), chronic systemic low-grade inflammation, intestinal environment, and nutrition and prospective views of probiotic and prebiotic interventions for the diseases.
\end{abstract}

Keywords: Obesity, Type 2 diabetes, Inflammation, Lipopolysaccharides, Intestinal bacteria, Probiotics, Prebiotics

\section{Background}

Obesity and overweight are world-wide health problems afflicting various populations, regardless of age, gender, and ethnicity. Obesity and overweight are abnormal conditions with excess fat accumulation, and are often determined by body mass index (BMI); $\mathrm{BMI} \geq 25$ is overweight while $\mathrm{BMI} \geq 30$ is obesity. According to data from the National Health and Nutrition Examination Survey (NHANES) 2007-2008, 68.0\% of adults are overweight or obese, while $16.9 \%$ of children and adolescents are obese in the U.S. [1,2]. Although no significant increase in obesity was observed among U.S. adults over the past ten years, the prevalence of obesity (33.8\%) remains high. In contrast, the prevalence of obesity among U.S. children and adolescents has significantly increased over

\footnotetext{
* Correspondence: omaye@unr.edu

Department of Agriculture, Nutrition, and Veterinary Sciences, University of Nevada Reno, Reno, NV 89557, USA
}

\section{Ciomed Central}

the past few decades [2,3], alerting health agencies to the serious health-related issue which has become widespread in the young population. Obesity and overweight have been thought to be a consequence of energy imbalance consisting of over-consumption of energy-dense foods (i.e., high-fat and high-sugar diets) and physical inactivity. Data from NHANES 1971-2000 reveals that average energy intake has significantly increased from $2450 \mathrm{kcal}$ to $2618 \mathrm{kcal}$ for U.S. men and from $1542 \mathrm{kcal}$ to $1877 \mathrm{kcal}$ for U.S. women during the past three decades [4]. The increase in the average energy intake is attributed to increased intake of fats (in grams) and carbohydrates, primarily as consumption of beverages providing simple sugars [5]. Similarly, the averages of daily energy intake among U.S. children (3-19 years old) were $2280 \mathrm{kcal}$ (boys) and $1793 \mathrm{kcal}$ (girls), and the energy intake was positively associated with BMI percentile from the age of six [6]. 
Diabetes is characterized by impaired secretion and/or activity of insulin and increased levels of blood glucose. The estimated case number of type 2 diabetes worldwide in 2000 is 171 million, translating into $2.8 \%$ of total population [7]. Wild et. al. predict a continuous increased trend of type 2 diabetes along with a stable prevalence of obesity; for example, an estimated prevalence of type 2 diabetes is $4.4 \%$ in 2030. Diabetes is one of the main causes of death in the U.S. According to CDC, 25.8 million of U.S. people (including 7 million of undiagnosed diabetes) have diabetes, accounting for $8.3 \%$ of total population. In 2010, an additional 79 million of U.S. adults are estimated to have prediabetes in which blood glucose levels exceed the normal range. Total costs of diabetes in 2007 were $\$ 174$ billion, including $\$ 116$ billion of direct medical costs and $\$ 58$ billion of indirect costs (e.g., work loss, premature death, related disability) [8]. The epidemic of type 2 diabetes in the U.S. is associated with changes in diet, particularly an increase in intake of refined carbohydrates, including beverages, and decrease in intake of fiber during the past century [9].

Subsequently based on such national statistics, we could conclude that traditional approaches, such as diet and physical activity, have been unsuccessful in decreasing the prevalence of obesity and related diseases. Because these approaches strongly rely on individual's behavior and motivation, we should consider other novel science-based strategies for prevention and therapy of metabolic diseases, particularly for weight loss.

\section{Metabolic disease-associated inflammation and endotoxiaemia}

Obesity and overnutrition (long-term intake of high fat/ sugar diets) are positively associated with chronic systemic low-grade inflammation, oxidative stress, and risks of other metabolic diseases, such as type 2 diabetes, cardiovascular disease, and some types of cancer [10-12].

Intestinal inflammation is associated with high fat diets and is considered as an early event in obesity and insulin resistance [13,14]. Diets high in meat products contain lipopolysaccharides (LPS) which are inducers of Toll-like receptor 4 (TLR4) [15]. TLR4 is an innate immune receptor which is localized on the surface of various cells. LPS are found in the outer membrane of gram-negative bacteria (e.g., E. coli.) and serve as endotoxins. Toxicity is associated with the lipid portions of LPS, lipid A, in which all of fatty acids are saturated, while immunogenicity is caused by their polysaccharide portions which contain O-antigens [16]. Released lipid A initiates a series of immune responses in the circulation after bacteria are lysed by host immune system. The immune system includes LPS-detoxifying properties through the intestinal alkaline phosphatase (IAP)[17].
However, dietary LPS can trigger immune responses to the hosts due to their resistance to temperatures and low $\mathrm{pH}$, even though their carriers (e.g., meat products, processed foods) are edible [15,18]. LPS-induced TLR4 activation leads to inflammation by secreting proinflammatory cytokines and chemokines. Dietary fats increase absorption/plasma concentrations of LPS and TLR4 expression of mononuclear cells in normal humans [19]. Increases in the expression and activity of TLR4 and endotoxicity were observed in the monocytes of patients with metabolic syndrome [20]. LPS are internalized and transported by chylomicrons along with dietary fats in the circulation. These processes contribute to diet-induced systemic (either acute or chronic) inflammation and eventually the development of metabolic diseases, such as obesity, type 2 diabetes, and cardiovascular diseases, which are associated with chronic systemic low-grade inflammation [13,21]. A positive association was found between serum LPS activity and biomarkers of metabolic syndrome (e.g., triglyceride levels, insulin resistance, chronic inflammation) in type 1 diabetic patients [22]. Also, plasma levels of LPSbinding protein (LBP) were high in both obese-prone and high-fat-diet fed mice, compared to controls fed standard diets [23]. LBP is an acute phase protein to transfer LPS to CD14 on the cell surface and a biomarker of metabolic endotoxiaemia. In obese humans, compared to normal-weight controls, LBP levels were high and positively associated with biomarkers of metabolic syndrome and type 2 diabetes [24]. Thus, LPSinduced inflammation and endotoxiaemia are closely linked to obesity and type 2 diabetes.

\section{Dietary macronutrient-induced inflammation}

Metabolism and immune system are linked. Undernutrition results in immunosuppression or susceptibility to infection, while overnutrition (i.e., obesity) leads to immunoactivation or susceptibility to inflammatory diseases, such as diabetes. Overnutrition (long-term intake of high fat/sugar diets) and infection lead to chronic and acute inflammation through nutrient and pathogen sensing systems, respectively [25].

Dietary macronutrients can act as inducers of TLR4 activation [26-29]. Lipids are non-immunogenic and can be haptens. The nutrient and pathogen sensing systems are likely to recognize compounds with structural similarities (e.g., saturated fatty acids in diets, lipid A derived from pathogens) and subsequently lead to the same consequence, inflammation (i.e., chronic or acute). Obesityassociated chronic inflammation could be characterized by a continuous activation of the innate immune system [30] and induced by overnutrition. LPS-induced TLR4 activation seems to be involved in either acute (i.e., infection) or chronic (i.e., overrnutrition) inflammation. Saturated fatty acids, not unsaturated fatty acids, induce 
inflammatory responses through TLR4 activation [28]. Eicosapentaenoic acid $(\omega-3, \mathrm{C} 20: 5)$ and decosahexaenoic acid ( $\omega-3, \mathrm{C} 22: 6)$ are well-studied polyunsaturated fatty acids, which have exhibited anti-inflammatory and antidiabetic properties mainly in animal models [31-34]. These $\omega-3$ fatty acids down-regulate inflammation and adiposity by up-regulating adiponection via peroxisome proliferator-activated receptor gamma (PPAR $\gamma)$ activation and $\beta$-oxidation via PPAR $\gamma$ activation, respectively [34]. Similarly, lipid A containing unsaturated fatty acids are non-toxic and can serve as an antagonist against endotoxins $[35,36]$.

Among unsaturated fatty acids, conjugated linoleic acid (CLA) is a group of geometric and positional isomers of linoleic acid ( $\omega-6, \mathrm{C} 18: 2)$, and is found mainly in dairy products and synthesized in the rumen as an intermediate by gram-negative bacteria, Butyrivibrio fibrisolvens, during the biohydrogenation of linoleic acid to stearic acid [37]. Some Lactobacillus species also produce significant amounts of CLA [38] (see the section of "potentials of probiotics and prebiotics" below). CLA is a possible PPARy agonist [39], and has been shown to have health promoting properties such as anti-oxidant, anti-inflammatory, anti-carcinogenic, anti-atherogenic, and anti-obesity effects [40-44]. CLA exhibited dose-dependent differential effects (i.e., prooxidant or antioxidant, cytotoxic) associated with redoxsensitive transcription factors PPAR $\gamma$ and NF-B in human endothelial cells $[44,45]$. These transcription factors seem to modulate oxidative stress and inflammation in a coordinated fashion, depending on micro-environmental factors [46]. Anti-obesity effects of CLA in humans are supported by two meta-analyses of Whigham et al. [47,48]. Kennedy et al. [40] conclude in their review that anti-obesogenic effects of CLA are due to: 1) reduction of energy intake with suppressed appetite, 2) induction of energy expenditure in white adipose tissue, muscles, and liver tissue, 3 ) reduction of lipogenesis or adipogenesis, 4) induction of lipolysis, and 5) induction of adipocyte apoptosis.

In addition to dietary fats, dietary carbohydrates appear to be involved in inflammation through TLR4 activation. High glucose treatment induces TLR4 expression in human monocytes [26], while insulin reduces LPS-induced TLR4 activation and oxidative stress $[49,50]$. Free saturated fatty acids exacerbate the expression and activity of TLR4 which is induced by high glucose in human monocytes along with increases in superoxide generation, NF- $\mathrm{kB}$ activity, and pro-inflammatory factors [51]. A decrease in the levels of the insulin-sensitive glucose transporter (GLUT4) is a characteristic of type 2 diabetes and insulin resistance. Insulin resistance results from down-regulation of GLUT4 and glucose transport selectively in adipose tissue [52]. Reduced levels of GLUT4 found in type 2 diabetes appear to be in part due to GLUT4 expression suppressed by free fatty acids through PPAR $\gamma$ [53]. PPAR $\gamma$ is known to be an adipogenic factor which triggers adipocyte differentiation. However, PPARY agonists (e.g., thiazolidinediones) cause PPAR protein to dissociate from the GLUT4 gene promoter and improve insulin resistance, by blocking suppression of GLUT4 mediated by fatty acids (i.e., arachidonic acid) and/or TLR4 agonists (i.e., LPS) and inducing GLUT4 expression via PPAR $\gamma$ activation [53-55]. In summary, an association is suggested between dietary macronutrients, inflammation through TLR4 activation, redox-sensitive transcription pathways, and metabolic diseases.

\section{Involvement of intestinal bacteria in the pathogenesis of metabolic diseases}

Because the gut is exposed to foreign antigens in foods, the gut associated lymphoid tissue (GALT) has evolved mechanisms to avoid strong immune responses to food antigens and to protect against pathogenic organisms derived from foods. Human gut bacteria consist of approximately $10^{14}$ colony-forming-unit (cfu) $/ \mathrm{mL}$ and 500 to1000 species and live in symbiosis with their host [56]. Bacteroidetes and Firmicutes are dominant ( $>90 \%$ of total microbial population) in the normal mouse and human intestines [57]. Bacteroidetes and Firmicutes play a role in nutrient absorption, mucosal barrier fortification, xenobiotic metabolism, angiogenesis, and postnatal intestinal maturation [57-59]. The population of these bacteria is controlled by diets (i.e., high fat) [60], and is crucial in development of obesity and diabetes $[57,61,62]$. The relative abundance of Bacteroidetes was higher in diabetic-prone rats with the development of diabetes than those without the development [61]. A decrease in Bacteroidetes and increase in Firmicutes were observed in obese humans and mice $[57,60]$. The changes in these phyla depend on diets (i.e. high fat) regardless of phenotypes (i.e., lean, obeseprone, obese-resistant) $[60,62]$. In addition, differences in types of immune cells present in the adipose tissue of obese and lean mice may be a consequence of differences in microbial composition [63].

Recent findings that support the idea of the involvement of intestinal bacteria in the development of obesity and diabetes include: 1) the resistance to high-fat diet-induced obesity in germ-free mice [64], 2) antibiotic-induced reduction of plasma LPS levels in obese mice fed a high-fat diet [65], and 3) delayed onset and development of type 1 diabetes by use of antibiotics in a diabetes-prone rat model [61]. Also, chronic intake of high-fat diets modulate intestinal inflammation through alteration of intestinal environment, such as intestinal permeability, microbial composition, and LPS-detoxifying ability of the intestinal alkaline phosphatase (IAP: an LPS detoxifying enzyme) activity $[62,66]$. Certain types of intestinal bacteria appear to serve as sources of LPS through the translocation of LPS and/or bacteria $[67,68]$ 
leading to chronic low-grade inflammation locally and/or systemically. Furthermore, these studies reveal that energy imbalance, which results from high calorie diet and physical inactivity, is not the only factor to attribute to development of obesity and metabolic diseases.

Thus, specific intestinal bacteria may provide LPS to induce low-grade inflammation locally and/or systemically through the translocation of intestinal bacteria and/ or their products, and play a role in host metabolism. Since the mechanistic links are suggested mainly in animal models, further investigation is needed to determine mechanisms in humans.

\section{Potentials of probiotics and prebiotics}

Probiotics, such as Lactobacilli and Bifidobacteria, are defined as "live microbial feed supplements which beneficially affect the host animal by improving its intestinal microbial balance"[69]. Prebiotics are non-digestible, fermentable carbohydrates and fibers, such as inulin-type frucans and galacto-oligosaccharides, which exhibit health promoting properties to host through selective stimulation of growth and/or activities of a limited number of bacteria (i.e., probiotics). Since probiotic- and prebiotic- induced health promoting effects are likely to be attributed to their ability to antagonize pathogenic bacteria and to modulate host immune responses $[70,71]$, earlier studies mainly focused on the relationship between probiotics/prebiotics and immune diseases (e.g., atopic disease, asthma) and infant nutrition [7274]. In 2007, Gordon and his colleagues first reported the involvement of intestinal microbes in obesogenesis [64]. Afterward, some investigators have documented that altered intestinal environment (i.e., microbial composition, intestinal permeability, LPS-detoxifying ability) could contribute to adiposity and insulin resistance $[61,62,64-66,75]$, as described in the previous section. Several investigations have been done on the effects of probiotics and prebiotics for obesity and diabetes [68,7679].

Investigation of probiotics (e.g., Lactobacilli, Bifidobacteria) and prebiotics (e.g., inulin, oligofructose) have lead to the suggestion that these supplements could have preventative and therapeutic potentials for immune diseases, exhibiting bacteria-specific immunomodulatory properties [71,80-82]. First, probiotics, such as Lactobacillus casei, Lactobacillus paracasei, Lactobacillus acidophilus, and Bifidobacterium animalis, can survive and grow at 20-40\% of the estimated survival rate in the GI tracts after their oral administration and increase their population in the intestines [83-85]. Low abundance of Lactobacilli and Bifidobacteria is associated with development of type 1 diabetes [86]. Similarly, high levels of Lactobacillus casei/ paracasei and Lactobacillus plantarum in human gut are negatively associated with obesity, but high levels of Lactobacillus reuteri are positively associated [68,87]. In addition, Lactobacillus species were decreased in the distal esophagus of rats fed a high fat diet, compared to those fed the standard diet [88]. Yogurt containing Lactobacillus acidophilus exhibits anti-cholesterolemic properties in mature boars [89]. Anti-inflammatory effects of probiotics, Lactobacillus casei, are negatively associated with NF-кB p50/p65 activation [90], which is induced by LPS through TLR4 activation, and positively associated with PPAR $\gamma$ activation [91].

Anti-obesity effects were observed in C57BL/6 J dietinduced obese mice supplemented with $1 \times 10^{9}$ colonyforming unit (cfu) of Lactobacillus rhamnosus PL60 which can produce CLA [79]. CLA are also produced from linoleic acid by Lactobacillus acidophilus, Lactobacillus plantarum, Lactobacillus paracasei, and Lactobacillus casei in vitro and in vivo (i.e., mice) $[38,92]$. CLA-induced adverse effects, such as increased insulin resistance and inflammation, have been observed mainly by use of single purified CLA isomer (in particular the trans-10, cis-12 CLA isomer) through NF-кB p50/p65 activation [93-95], while CLA producing Lactobacillus species (e.g., L. casei, L. plantarum) exhibited anti- inflammatory effects along with increased PPAR $\gamma$ expression [92]. CLA produced by probiotics in vivo appears to remain within the intestinal lumen and serve as a PPARY agonist locally, whereas orally supplemented CLA seems to be absorbed and affect systemically [96].

As for prebiotics, Parnell and Reimer demonstrated that obese and lean rats fed a diet containing inulin and oligofructose $(0,10,20 \% \mathrm{w} / \mathrm{w})$ increased anorexigenic peptide levels and probiotic population and decreased glucagon levels in a dose-dependent manner. However, no significant changes in body weight or blood insulin/glucose were observed between rats fed with or without prebiotics [77]. In contrast, prebiotic treatments $(0.3 \mathrm{~g} /$ mouse/day $)$ exhibited anti-obesity, anti-diabetic, antioxidant, and antiinflammatory effects in obese mice and altered intestinal microbial composition [76].

Exosaccharides or extracelluar polysaccharides (EPS) consisting of sugar residues are bound to the cell surface of gram-positive/negative bacteria, or secreted as soluble/insoluble polymers [97]. Probiotic-derived EPS are counterparts of LPS produced by pathogenic bacteria, and antagonize the bacteria and endotoxins [98,99]. EPS is heat resistant with its degradation temperature of $260{ }^{\circ} \mathrm{C}$ [100], similar to LPS. Supplementation of EPS isolated from Bifidobacterium results in immunomodulatory effects ( $5 \mathrm{~g} / \mathrm{mL}$ of EPS) in macrophages and antimicrobial effects against pathogenic bacteria $(80 \mathrm{~g} / \mathrm{mL}$ of EPS) [101]. Oral administration of EPS (100 mg/kg body weight/day of Lactobacillus kefiranofaciens for 2 to 7 days) effectively induces systemic immunity through 


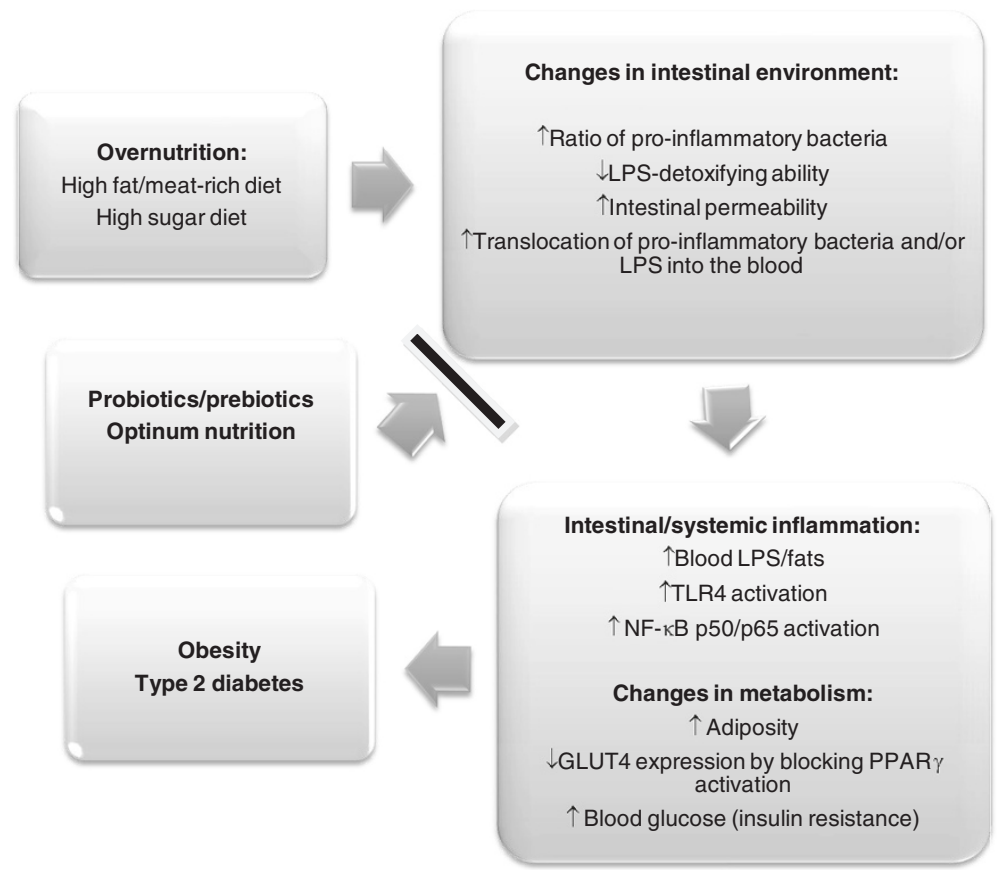

Figure 1 Mechanistic links of metabolic diseases. Overnutrition (chronic intake of high fat/sugar diets) may modulate intestinal environment, and subsequently may lead to chronic low-grade inflammation locally and systemically and alter metabolism.

cytokines released into the circulating blood of mice [102]. Hypoglycemic effects of EPS derived from mushrooms (Tremella fuciformis and Phellinus baumii) were observed in obese mice, and the effects were associated with increased PPARY expression [103]. Lactobacillus species-derived EPS (kefiran) prevents the onset and development of atherosclerosis in hypercholesterolemic rabbits fed diet with $1 \% \mathrm{w} / \mathrm{w}$ kefiran through anti- inflammatory and antioxidant properties [104]. EPS isolated from Lactobacillus paracasei exhibits immunomodulatory and antioxidant properties in a dose-dependent manner [105].

Therefore, one is lead to speculate that health promoting properties of probiotics could be related to PPAR $\gamma$ activation through their products by antagonizing intestinal proinflammatory bacteria, blocking the NF-KB p50/p65

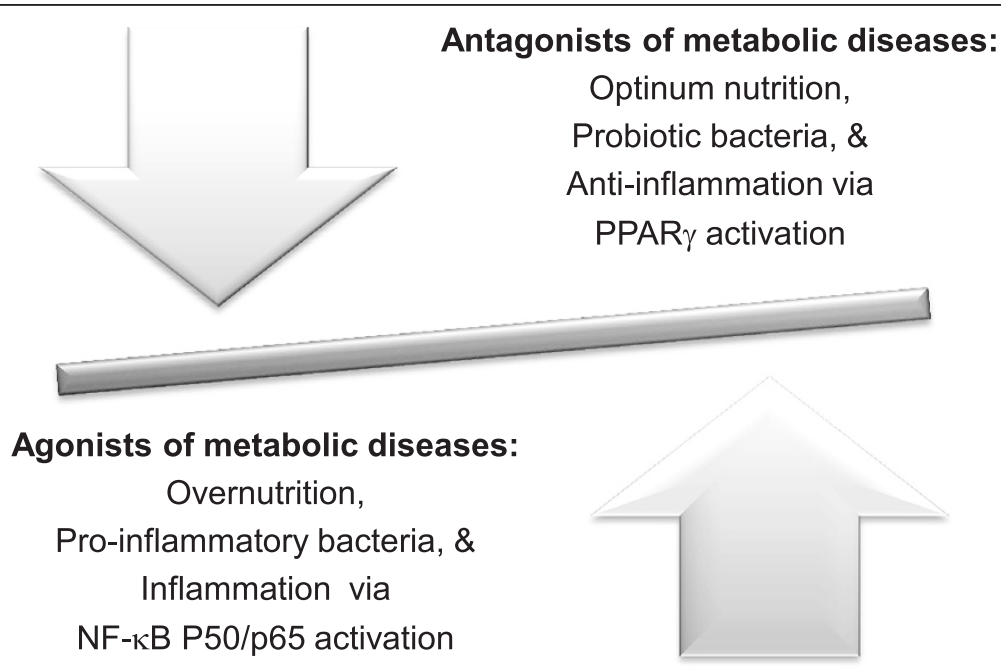

Figure 2 Relationships at microbial and molecular levels in metabolic diseases. Nutrition status, classes/species of intestinal bacteria, and signaling pathways could be determinants in the development of metabolic diseases and be expressed as agonists (inducers) or antagonists (suppressors) of the diseases. 
activation which is induced by LPS derived from the bacteria, and modulating intestinal environment/microbial composition. Clinical trials of pro-/prebiotic intervention are needed, as the speculation is attributed to mainly results from animal studies.

\section{Conclusions: Prospective insights}

Mechanistic links of metabolic diseases are shown in Figure 1. Optimum nutrition includes long-term intake of diets rich in unrefined carbohydrates (or fibers/prebiotics), while overnutrition refers to longterm intake of diets high in fats/meat (particularly saturated fats) and refined carbohydrates (or simple sugars). Chronic intake of diets high in fats and sugars may alter intestinal environment, including microbial composition and mucosal structure/functions, and result in a vulnerable microbial barrier and increased permeability of the intestines or leaky gut [67]. These changes allow intestinal bacteria and/or LPS to move into the circulation, and eventually lead to chronic systemic low-grade inflammation associated with metabolic diseases $[67,106]$. Nutrition status, classes/species of intestinal bacteria, and signaling pathways could be classified as agonists (or inducers) or antagonists (or suppressors) of metabolic diseases. Overnutrition, increased ratio of pro-inflammatory bacteria to total intestinal bacteria, and NF- $\mathrm{KB}$ p50/ p65 activation could serve as agonists of metabolic diseases, whereas optimum nutrition, optimum ratio of probiotic bacteria (e.g., Lactobacilli, Bifidobacteria), and PPAR $\gamma$ activation could act as antagonists of the diseases (Figure 2). The antagonists may be able to alleviate or reverse processes induced by the agonists. As previously described, classes/species and/or ratio of pro-inflammatory bacteria remain to be determined because the results of existing investigations were inconclusive. Further research are needed to clarify classes/species or ratio of the bacteria to total bacterial population.

The control of intestinal microbial composition by use of probiotics and prebiotics is likely to impact the development of metabolic diseases through modulation of immune responses/inflammation and metabolism. Supplementation of probiotics and prebiotics may delay and/or reverse the progression of metabolic diseases. Additional preclinical and clinical investigations are warranted to determine the relationship between metabolism and immune system and the efficacy of probiotics and prebiotics as preventative and therapeutic means for metabolic diseases.

\section{Abbreviations}

LPS: Lipopolysaccharides; TLR: Toll-like receptors; GLUT4: Glucose transporter 4; EPS: Extracellular polysaccharides; CLA: Conjugated linoleic acid; PPARY: Peroxisome proliferator-activated receptor gamma; NF-kB: Nuclear factor kappa B.
Competing interests

The authors declare that they have no competing interests.

\section{Authors' contributions}

Both authors participated in the preparation of the manuscript, and read and approved the final manuscript.

Received: 29 March 2012 Accepted: 19 June 2012

Published: 19 June 2012

\section{References}

1. Flegal KM, Carroll MD, Ogden CL, Curtin LR: Prevalence and trends in obesity among US adults, 1999-2008. JAMA 2010, 303:235-241.

2. Ogden $\mathrm{CL}$, Carroll MD: Prevalence of obesity among children and adolescents: United States, Trends 1963-1965 through 2007-2008. In Centers of Disease Control and Prevention, National Center for Health Statistics June 2010. Atlanta:; 2010:1-5.

3. Ogden CL, Carroll MD, Curtin LR, McDowell MA, Tabak CJ, Flegal KM: Prevalence of overweight and obesity in the United States, 1999-2004. JAMA 2006, 295:1549-1555.

4. Wright JD, Kennedy-Stephenson J, Wang CY, McDowell MA, Johnson CL: Trends in intake of energy and macronutrients: United States, 19712000. In Centers of Disease Control and Prevention. Atlanta:; 2004:80-82.

5. Chanmugam P, Guthrie JF, Cecilio S, Morton JF, Basiotis PP, Anand R: Did fat intake in the United States really decline between 1989-1991 and 1994-1996? J Am Diet Assoc 2003, 103:867-872.

6. Huang TT, Howarth NC, Lin BH, Roberts SB, McCrory MA: Energy intake and meal portions: associations with BMI percentile in U.S. children. Obes Res 2004, 12:1875-1885.

7. Wild S, Roglic G, Green A, Sicree R, King H: Global prevalence of diabetes: estimates for the year 2000 and projections for 2030. Diabetes Care 2004, 27:1047-1053.

8. Centers of Disease Control and Prevention: Diabetes:, [http://www.cdc.gov/ chronicdisease/resources/publications/AAG/ddt.htm\#aag].

9. Gross LS, Li L, Ford ES, Liu S: Increased consumption of refined carbohydrates and the epidemic of type 2 diabetes in the United States: an ecologic assessment. Am J Clin Nutr 2004, 79:774-779.

10. Shoelson SE, Herrero L, Naaz A: Obesity, inflammation, and insulin resistance. Gastroenterology 2007, 132:2169-2180.

11. Vincent HK, Innes KE, Vincent KR: Oxidative stress and potential interventions to reduce oxidative stress in overweight and obesity. Diabetes Obes Metab 2007, 9:813-839.

12. Styskal J, Remmen HV, Richardson A, Salmon AB: Oxidative stress and diabetes: What can we learn about insulin resistance from antioxidant mutant mouse models? Free Radical Biol Med 2012, 52:46-58.

13. Ji Y, Sakata Y, Tso P: Nutrient-induced inflammation in the intestine. Curr Opin Clin Nutr 2011, 14:315-321.

14. Ding S, Lund PK: Role of intestinal inflammation as an early event in obesity and insulin resistance. Curr OpinClin Nutr 2011, 14:328-333.

15. Erridge C: The capacity of food stuffs to induce innate immune activation of human monocytes in vitro is dependent on food content of stimulants of Toll-like receptors 2 and 4. Br J Nutr 2011, 105:15-23.

16. Todar K: Online Textbook of Bacteriology. 2011, Bacterial Endotoxin. [textbookofbacteriology.net/endotoxin.html]

17. Bates JM, Akerlund J, Mittge E, Guillemin K: Intestinal alkaline phosphatase detoxifies lipopolysaccharide and prevents inflammation in response to the gut microbiota. Cell Host Microbe 2009, 2:371-382.

18. Erridge C: Accumulation of stimulants of Toll-like receptor (TLR)-2 and TLR4 in meat products stored at 5'C. J Food Sci 2011, 76:H72-79.

19. Deopurkar R, Ghanim H, Friedman J, Abuaysheh S, Sia CL, Mohanty P, Viswanathan P, Chaudhuri A, Dandona P: Differential effects of cream, glucose, and orange juice on inflammation, endotoxin, and the expression of Toll-like receptor-4 and suppressor of cytokine signaling-3. Diabetes Care 2010, 33:991-997.

20. Jialal I, Huet BA, Kaur H, Chien A, Devaraj S: Increased Toll-like receptor activity in patients with metabolic syndrome. Diabetes Care 2012, 35:900-904.

21. Ghoshal S, Witta J, Zhong J, de Williers W, Eckhardt E: Chylomicrons promote intestinal absorption of lipopolysaccharides. J Lipid Res 2009, 50:90-97. 
22. Lassenius MI, Pietilainen KH, Kaartinen K, Pussinen PJ, Syrjanen J, Forsblom C, Porsti I, Rissanen A, Kaprio J, Mustonen J, Groop PH, Lehto M: Bacterial endotoxin activity in human serum is associated with dyslipidemia, insulin resistance, obesity, and chronic inflammation. Diabetes Care 2011 34:1809-1815

23. Nakarai H, Yamashita A, Nagayasu S, Iwashita M, Kumamoto S, Ohyama H, Hata M, Soga Y, Kushiyama A, Asano T, Abiko Y, Nishimura F: Adopocytemacrophage interaction may mediate LPS-induced low-grade inflammation: potential link with metabolic complications. Innate Immun 2011, 18:164-170.

24. Sun L, Yu Z, Ye X, Zou S, Li H, Yu D, Wu H, Chen Y, Dore J, Clement K, Hu $F B$, Lin $X: A$ marker of endotoxemia is associated with obesity and related metabolic disorders in apparently healthy Chinese. Diabetes Care 2010, 33:1925-1932

25. Wellen KE, Hotamisligil GS: Inflammation, stress, and diabetes. J Clin Invest 2005, 115:1111-1119.

26. Dasu MR, Devaraj S, Zhao L, Hwang DH, Jialal I: High glucose induced Tolllike receptor expression in human monocytes. Diabetes 2008, 57:30903098.

27. Lee JY, Sohn KH, Rhee SH, Hwang D: Saturated fatty acids, but not unsaturated fatty acids, induce the expression of cyclooxygenase-2 mediated through Toll-like receptor 4. J Biol Chem 2001, 276:1668316689.

28. Wong SW, Kwon MJ, Choi AMK, Kim HP, Nakahara K, Hwang DH: Fatty acids modulate Toll-like receptor 4 activation through regulation of receptor dimerization and recruitment into lipid rafts in a reactive oxygen species-dependent manner. J Biol Chem 2009, 284:27384-27392.

29. Dandona P, Ghanim H, Chaudhuri A, Dhindsa S, Kim SS: Macronutrient intake induces oxidative and inflammatory stress: potential relevance to atherosclerosis and insulin resistence. Exp Mol Med 2010, 42:245-253.

30. Nijhuis J, Rensen SS, Slaats Y, van Dielen FMH, Buurman WA, Greve JWM: Neutrophil activation in morbid obesity, chronic activation of acute inflammation. Obesity 2009, 17:2014-2018.

31. Kelley DS, Adkins Y: Similarities and differences between the effects of EPA and DHA on markers of atherosclerosis in human subjects. $P$ Nutr Soc 2012, 28:1-10.

32. Fedor D, Kelley DS: Prevention of insulin resistance by $n-3$ polyunsaturarted fatty acids. Curr Opin Clin Nutr 2009, 12:138-146.

33. Kalupahana NS, Claycombe KJ, Newman SJ, Stewart T, Siriwardhana N, Mathhan N, Lichtenstein AH, Moustaid-Moussa N: Eicosapentaenoic acid prevents and reverses insulin resistance in high-fat diet-induced obese mice via modulation of adipose tissue inflammation. J Nutr 2010, 140:1915-1922.

34. Kalupahana NS, Claycombe KJ, Moustaid-Moussa N: (n-3) Fatty acids alleviate adipose tissue inflammation and insulin resistance: mechanistic insights. Adv Nutr 2011, 2:304-316.

35. Frauss JH, Seydel U, Weckesser J, Mayer H: Structural analysis of the nontoxic lipid A of Rhodobacter capsulatus 37b4. Eur J Biochem 1989, 180:519-526.

36. Qureshi N, Takayama K, Kurtz R: Diphosphoryl lipid A obtained from the nontoxic lipopolysaccharide of Rhodopseudomonas sphaeroides is an endotoxin antagonist in mice. Infect Immun 1991, 59:441-444.

37. Lawson RE, Moss AR, Givens DI: The role of dairy products in supplying conjugated linoleic acid to man's diet: a review. Nutr Res Rev 2001 14:153-172.

38. Kishino S, Ogawa J, Omura Y, Matsumura K, Shimuzu S: Conjugated linoleic acid production from linoleic acid by lactic acid bacteria. JAOCS 2002, 79:159-163.

39. Belury MA: Dietary conjugated linoleic acid in health: physiological effects and mechanisms of action. Annu Rev Nutr 2002, 22:505-531.

40. Kennedy A, Martinez K, Schmidt S, Mandrup S, Lapoint K, McIntosh MK: Antiobesity mechanisms of action of conjugated linoleic acid. J Nutr Biochem 2010, 21:171-179.

41. Nakamura YK, Omaye ST: Conjugated linoleic acid modulation of risk factors associated with atherosclerosis. Nutr Metab 2008, 5:22.

42. Bassaganya-Riera J, Hontecillas R: Dietary conjugated linoleic acid and n-3 polyunsaturated fatty acids in inflammatory bowel disease. Curr Opin Clin Nutr 2010, 13:569-573.

43. Bougnoux P, Hajiaji N, Maheo K, Couet C, Chevalier S: Fatty acids and breast cancer: sensitization to treatments and prevention of metastatic re-growth. Prog Lipid Res 2010, 49:76-86.
44. Nakamura YK, Omaye ST: Conjugated linoleic acid isomers' roles in the regulation of PPARY and NF-KBDNA binding and subsequent expression of antioxidant enzymes in human umbilical vein endothelial cells. Nutrition 2009, 25:800-811.

45. Nakamura YK, Dubick MA, Omaye ST: Modulation of oxidative stress by gamma-glutamylcysteine (GGC) and conjugated linoleic acid (CLA) in human umbilical vein endothelial cells. Food Chem Tox 2012, 50:18541859

46. Nakamura YK, Omaye ST: Lipophilic compound-mediated gene expression and implication for intervention in reactive oxygen species (ROS)-related diseases: mini-review. Nutrients 2010, 2:725-736.

47. Schoeller DA, Watras AC, Whigham LD: A meta-analysis of the effects of conjugated linoleic acid on fat-free mass in humans. Appl Physiol Nutr Me 2009, 34:975-978.

48. Whigham LD, Watras AC, Schoeller DA: Efficacy of conjugated linoleic acid for reducing fat mass: a meta-analysis in humans. Am J Clin Nutr 2007 85:1203-1211.

49. Dandona P, Ghanim H, Bandyopadhyay A, Korzeniewski K, Ling Sia C, Chaudhuri A: Insulin suppresses endotoxin-induced oxidative, nitrosative, and inflammatory stress in humans. Diabetes Care 2010, 33:2416-2423.

50. Dandona P, Chaudhuri A, Ghanim H, Mohanty P: Insulin as an antiinflammatory and antiatherogenic modulator. J Am Coll Cardiol 2009, 53: S14-S20.

51. Dasu MR, Jialal I: Free fatty acids in the presence of hugh glucose amplify monocyte inflammation via Toll-like receptors. Am J Physiol- Endoc 2011, 300:E145-154

52. Abel ED, Peroni O, Kim JK, Boss O, Hadro E, Minnemann T, Shulman Gl, Kahn BB: Adipose-selective targeting of the GLUT4 gene impairs insulin action in muscle and liver. Nature 2001, 409:729-733.

53. Armoni M, Harel C, Bar-Yoseph F, Milo S, Karnieli E: Free fatty acids repress the GLUT4 gene expression in cardiac muscle via novel response elements. J Biol Chem 2005, 280:34786-34795.

54. Karnieli E, Armoni M: Transcriptional regulation of the insulin-responsive glucose transporter GLUT4 gene: from physiology to pathology. Am J Physiol-Endoc 2008, 295:E38-E45.

55. Franchini M, Monnais E, Seboek D, Radimerski T, Zini E, Kaufmann K, Lutz T, Reusch C, Ackermann M, Muller B, Linscheid P: Insulin resistance and increased lipolysis in bone marrow derived adipocytes stimulated with agonists of Toll like receptors. Horm Metab Res 2010, 42:703-709.

56. Janeway CAJr, Travers P, Walport M, Shlomchik MJ: Adaptive Immunity to Infection, in Immunobiology. In Immunobiology: the immune system in health and disease. 6th edition. Edited by Bachmann M, Casadevall A, Doherty P, Hengartner H, McGhee J, Potter M. New York: Garland Science; 2005:409-459.

57. Ley RE, Turnbaugh PJ, Klein S, Gordon Jl: Human gut microbes associated with obesity. Nature 2006, 444:1022-1023.

58. Hooper LV, Wong MH, Thelin A, Hansson L, Falk PG, Gordon Jl: Molecular analysis of commensal host-microbial relationships in the intestine. Science 2001, 291:881-884.

59. DiBaise JK, Zhang H, Crowell MD, Karajmalnik-Brown R, Decker GA, Rittmann BE: Gut microbiota and its possible relationship with obesity. Mayo Clin Proc 2008, 83:460-469.

60. Hildebrandt MA, Hoffmann C, Shrerrill-Mix SA, Keilbaugh SA, Hamady M, Chen YY, Knight R, Ahima RS, Bushman F, Wu GD: High fat diet determines the composition of the murine gut microbiome independently of obesity. Gastroenterology 2009, 137(Hoffmann C):1716-1724

61. Brugman S, Klatter FA, Visser JTJ, Wildeboer-Veloo ACM, Harmsen HJM, Rozing J, Bos NA: Antibiotic treatment partially protects against type 1 diabetes in the Bio-Breeding diabetes-prone rat. Is the gut flora involved in the developmet of type 1 diabetes? Diabetologia 2006, 49:2105-2108.

62. De La Serre CB, Ellis CL, Lee J, Hartman AL, Rutledge JC, Raybould HE: Propensity to high-fat diet-induced obesity in rats is associated with changes in the gut microbiota and gut inflammation. Am J Physiol Gastr 2010, 299:G440-448.

63. Kau AL, Ahern PP, Griffin NW, Goodman AL, Gordon J: Human nutrition, the gut microbiome and the immune system. Nature 2011, 474:327-336.

64. Backhed F, Manchester JK, Semenkovich CF, Gordon Jl: Mechanisms underlying the resistance to diet-induced obesity in germ-free mice. PNAS 2007, 104:979-984. 
65. Cani PD, Bibiloni R, Knauf C, Waget A, Neyrinck AM, Delzenne NM, Burcelin $R$ : Changes in gut microbiota control metabolic enfotoxemia-induced inflammation in high-fat diet-induced obesity and diabetes in mice. Diabetes 2008, 57:1470-1481.

66. Malo MS, Alam SN, Mostafa G, Zeller SJ, Johnson PV, Mohammad N, Chen KT, Moss AK, Ramasamy S, Faruqui A, Hodin S, Malo PS, Ebrahimi F, Biswas B, Narisawa S, Millan JL, Warren HS, Kaplan JS, Kitts CL, Hohmann EL, Hodin RA: Intestinal alkaline phosphatase preserves the normal homeostasis of gut microbiota. Gut 2010, 59:1476-1484.

67. Sekirov I, Russell SL, Antunes CM, Finlay BB: Gut microbiota in health and disease. Physiol Rev 2010, 90:859-904

68. Amar J, Chabo C, Waget A, Klopp P, Vachoux C, Bermudez-Humaran LG, Smirnova N, Berge M, Sulpice T, Lahtinen S, Ouwehand A, Langella P, Raurtonen N, Sansonetti PJ, Burcelin R: Intestinal mucosal adherence and translocation of commensal bacteria at the early onset of type 2 diabetes: molecular mechanisms and probiotic treatment. EMBO Mol Med 2011, 3:559-572.

69. Fuller R: Probiotics in man and animals. J App/ Bacteriol 1989, 66:365-378.

70. Roberfroid M, Gibson GR, Hoyles L, McCartney AL, Rastall R, Rowland I, Wolvers D, Watzl B, Szajewska H, Stahl B, Guarner F, Respondek F, Whelan K, Coxam V, Davicco MJ, Leotoing L, Wittrant Y, Delzenne NM, Cani PD, Neyrinck AM, Meheust A: Prebiotic effects: metabolic and health benefits. Br J Nutr 2010, 104:S1-S63.

71. Yan F, Polk DB: Probiotics and immune health. Curr Opin Gastroen 2011, 27:496-501.

72. Parracho $H$, McCartney AL, Gibson GR: Probiotics and prebiotics in infant nutrition. Proc Nutr Soc 2007, 66:405-411.

73. Rautava S, Kalliomaki M, Isolauri E: Probiotics during pregnancy and breast-feeding might confer immunomodulatory protection agaist atopic disease in the infant. J Allergy Clin Immun 2002, 109:119-121.

74. Bjorksten B: Evidence of probiotics in prevention of allergy and asthma. Curr Drug Targets. Inflam Allergy 2005, 4:599-604.

75. Delzenne NM, Neyrinck AM, Backhed F, Cani PD: Targeting gut microbiota in obesity: effects of prebiotics and probiotics. Nature Rev Endocrinol 2011, 7:639-646.

76. Everard A, Lazarevis V, Derrien M, Girard M, Muccioli GG, Neyrinck AM, Possemiers S, van Holle A, Francois P, de Vos WM, Delzenne NM, Schrenzel J, Cani PD: Response of gut microbiota and glucose and lipid metabolism to prebiotics in genetic obese and diet-induced leptinresistant mice. Diabetes 2011, 60:2775-2786

77. Parnell JA, Reimer RA: Prebiotic fibres dose-dependently increase satiety hormones and alter Bacteroides and Frimicutes in lean and obese JCR: LA-cp rats. Br J Nutr 2011, 18:1-13.

78. Cani PD, Delzenne NM: The gut microbiome as therapeutic target. Pharm Therapuet 2011, 130:202-212

79. Lee HY, Park JH, Seok SH, Baek MW, Kim DJ, Lee KE, Paek KS, Lee Y, Park JH: Human originated bacteria, Lactobacillus rhamnosus PL60, produce conjugated linoleic acid and show anti-obesity effects in diet-induced obese mice. Biochim Biophys Acta 2006, 1761:736-744.

80. Roberfroid M, Gibson GR, Hoyles L, McCartney AL, Rastall R, Rowland I, Wolvers D, Watzl B, Szajewska H, Stahl B, Guarner F, Respondek F, Whelan K, Coxam V, Davicco MJ, Leotoing L, Wittrant Y, Delzenne NM, Cani PD Neyrinck AM, Meheust A: Prebiotic effects: metabolic and health benefits. Br J Nutr 2007, 104:S1-S63.

81. He F, Morita H, Ouwehand AC: Bifidobacteria and Lactobacilli exhibited different mitogenic activity on murine splenocytes. Int J Prob Preb 2006, 1:77-82

82. Roller M, Rechkemmer G, Waltzl B: Prebiotic inulin enriched with oligofructose in combination with the probiotics Lactobacillus rhamnosus and Bifidobacterium lactis modulates intestinal immune functions in rats. J Nutr 2004, 134:153-156.

83. Lee YK, Ho PS, Low CS, Arvilommi H, Salminen S: Permanent colonization by Lactobacillus casei is hindered by the low rate of cell devision in mouse gut. Appl Environ Microb 2004, 70:670-674.

84. Bezkorovainy A: Probiotics: determinants of survival and growth in the gut. Am J Clin Nutr 1998, 73:399S-405S.

85. Roessler A, Forssten SD, Glei M, Ouwehand AC, Jahreis G: The effect of probiotics on faecal microbiota and genotoxic activity of faecal water in patients with atopic dermatitis: a randomized, placebo-controlled study. Clin Nutr 2011, 31:22-29.
86. Roesch LF, Lorca GL, Casella G, Giongo A, Naranjo A, Pionzio AM, Li N, Mai V, Wasserfall CH, Schatz D, Atkinson MA, Neu J, Triplett EW: Cultureindependent identification of gut bacteria correlated with the onset of diabetes in a rat model. ISME J 2009, 3:536-548.

87. Million M, Maraninchi M, Henry M, Armougom F, Richet $H$, Carrieri $P$, Valero $R$, Raccah D, Vialettes B, Raoult D: Obesity-associated gut microbiota is enriched in Lactobacillus reuteri and depleted in Bifidobacterium animalis and Methanobrevibacter smithii. Int J Obes, . in press.

88. Zhao X, Liu XW, Xie N, Wang XH, Cui Y, Yang JW, Chen LL, Lu FG: Lactobacillus species shift in distal esophagus of high-fat-diet-fed rats. World J Gastroentero 2011, 17:3151-3157.

89. Danielson AD, Peo ERJ, Shahani KM, Lewis AJ, Whalen PJ, Amer MA: Anticholesteremic property of Lactobacillus acidophilus yogurt fed to mature boars. J Anim Sci 1989, 67:966-974.

90. Tien MS, Girardin SE, Regnault B, Bourhis LL, Dillies MA, Coppee JY, BourdetSicard R, Sansonetti PJ, Pedron T: Anti-inflammatory effect of Lactobacillus casei on Shigella-infected human intestinal epithelial cells. Immun 2006, 176:1228-1237.

91. Eun CS, Han DS, Lee SH, Jeon YC, Sohn JH, Kim YS, Lee J: Probiotics may reduce inflammation by enhancing peroxisome proliferator activated receptor gamma activation in HT-29 cells. Korean J Gastroentero 2007, 49:139-146.

92. Ewaschuk JB, Walker JW, Diaz H, Madsen KL: Bioproduction of conjugated linoleic acid by probiotic bacteria occurs in vitro and in vivo in mice. $J$ Nutr 2006, 136:1483-1487.

93. Kennedy A, Martinez K, Chung S, LaPoint K, Hopkins R, Schmidt SF Andersen K, Mandrup S, Mclntosh MK: Inflammation and insulin resistance induced by trans-10, cis-12 conjugated linoleic acid depend on intracellular calcium levels in primary cultures of human adipocytes. $J$ Lipid Res 2010, 51:1906-1917.

94. Martinez K, Kennedy A, West T, Milatovic D, Aschner M, Mclntosh MK: Trans-10, cis-12 conjugated linoleic acid instigates inflammation in human adpocytes compared to preadipocytes. J Biol Chem 2010, 285:17701-17712

95. Halade GV, Rahman A, Fernandes G: Differential effects of conjugated linoleic acid isomers in insulin-resistant female C57BI/6J mice. J Nutr Biochem 2010, 21:332-337.

96. Bassaganya-Riera J, Viladomiu M, Pedradosa M, De Simone C, Carbo A, Shaykhutdinov R, Jobin C, Arthur JC, Corl BA, Vogel H, Storr M, Hontecillas R: Probiotic bacteria produce conjugated linoleic acid locally in the gut that targets macrophage PPARY to suppress colitis. PLOS ONE 2012, 7: e31238.

97. Kumar AS, Mody K, Jha B: Bacterial exopolysaccharides - a perception. J Basic Microb 2007, 47:103-117.

98. Ruas-Madiedo P, Gueimonde M, Margolles A, DIR-G CG, Salminen S: Exopolysaccharides produced by probiotic strains modify the adhesion of probiotics and enteropathogens to human intestinal mucus. J Food Protect 2006, 69:2011-2015.

99. Ruas-Madiedo P, Medrano M, Salazar N, DLR-G CG, Perez PF, Abraham AG: Exopolysaccharides produced by Lactobacillus and Bifidobacterium strains abrogate in vitro the cytotoxic effect of bacterial toxins on eukaryotic cells. J Appl Microb 2010, 109:2079-2086.

100. Ismail B, Nampoothiri KM: Production, purification and structural characterization of an exopolysaccharide produced by a probiotic Lactobacillus plantarum MTCC9510. Arch Microbiol 2010, 192:1049-1057.

101. Wu MH, Pan TM, Wu YJ, Chang SJ, Chang MS, Hu CY: Exopolysaccharide activities from probiotic bifidobacterium: Immunomodulatory effects (on J774A.1 macrophages) and antimicrobial properties. Int J Food Microbiol 2010, 144:104-110

102. Vinderola G, Perdigon G, Duarte J, Farnworth E, Matar C: Effects of the oral administration of the exopolysaccharide produced by Lactobacillus kefiranofaciens on the gut mucosal immunity. Cytokine 2006, 36:254-260.

103. Cho EJ, Hwang HJ, Kim SW, Oh JY, Baek YM, Choi JW, Bae SH, Yun JW: Hypoglycemic effects of exopolysaccharides produced by mycelial cultures of two different mushrooms Tremella fuciformisand Phellinus baumii in ob/ob mice. Appl Microbiol Biot 2007, 75:1257-1265.

104. Uchida M, Ishii I, Inoue C, Akisato Y. Watanabe K, Hosoyama S, Toida T, Ariyoshi N, Kitada M: Kefiran reduces atherosclerosis in rabbits fed a high cholesterol diet. J Atherosclerosis Thromb 2010, 17:980-988. 
105. Liu CF, Tseng KC, Chiang SS, Lee BH, Hsu WH, Pan TM: Immunomodulatory and antioxidantpotential of Lactobacillus exopolysaccharides. I Sci Food Agr 2011, 91:2284-2291.

106. Delzenne NM, Neyrinck AM, Cani PD: Modulation of the gut microbiota by nutrients with prebiotic properties: consequences for host health in the context of obesity and metabolic syndrome. MicrobCell Fact 2011, 10:S10.

doi:10.1186/1743-7075-9-60

Cite this article as: Nakamura and Omaye: Metabolic diseases and pro- and prebiotics: Mechanistic insights. Nutrition \& Metabolism 2012

\section{Submit your next manuscript to BioMed Central and take full advantage of:}

- Convenient online submission

- Thorough peer review

- No space constraints or color figure charges

- Immediate publication on acceptance

- Inclusion in PubMed, CAS, Scopus and Google Scholar

- Research which is freely available for redistribution 